\title{
OCCUPATIONAL BURNOUT AMONG WORKERS IN THE LONG-TERM CARE SECTOR IN RELATION TO THEIR PERSONALITY TRAITS
}

\author{
ANNA KANIOS $^{1}$ and ANNA BOCHEŃSKA-BRANDT ${ }^{2}$ \\ ${ }^{1}$ Maria Curie-Skłodowska University, Lublin, Poland \\ Faculty of Pedagogy and Psychology, Department of Social Pedagogy \\ ${ }^{2}$ Ludwig Fresenius Schulen, Hannover gem. GmbH, Germany
}

\begin{abstract}
Objectives: This paper investigates the sense of occupational burnout among people working with older persons in the long-term care sector in relation to their personality traits. The study objective is to examine the correlation between the sense of burnout and personality traits of persons working in the helping professions, the so-called human services. According to researchers, these professionals are susceptible to occupational burnout due to the involvement of their personal emotions in the helping process. Material and Methods: The study encompassed 238 workers employed at care institutions for older people. The authors used a diagnostic survey as the research method, and the following research instruments: the Maslach Burnout Inventory by C. Maslach (to assess an individual's sense of burnout) and the NEO Five-Factor Inventory by P.T. Costa and R.R. McCrae (to assess personality traits). Results: The survey indicates that workers are at risk of occupational burnout, and statistically significant differences have been observed in their sense of burnout depending on their personality traits in all the inventories analyzed: emotional exhaustion, depersonalization, and personal accomplishment. Conclusions: Since the survey results confirm the differences in the sense of occupational burnout among the respondents with different personality traits, measures should be taken for the prevention and early detection of burnout in workers. For the intervention methods to be effective, workers' personality traits should be taken into account. Int J Occup Med Environ Health. 2021;34(4):491-504
\end{abstract}

Key words:

Poland, worker, occupational burnout, personality traits, older person, long-term care sector

\section{INTRODUCTION}

The number of dependent older persons in Poland has been rising systematically. In 2017, Poland had a population of 38.4 million, including $>9$ million people aged $\geq 60$ (>24\%). People aged 60-64 are the most numerous group (nearly one-third) in the subpopulation of older people, while people aged $\geq 80$ account for $18 \%$ [1].

Demographic projections show that the percentage of people aged 65 will be increasing systematically and is expected to reach $23.2 \%$ in 2035 . Gerontologists highlight the phenomenon known as double ageing, manifested in the fast growth of the population of people aged $\geq 65$ with the concurrent increase in the percentage of people aged $\geq 80$, i.e., people in advanced old age [2].

Furthermore, data from Poland's Central Statistical Office indicate that during the last 30 years, the number of people aged $>75$ in Poland has doubled, while the number of those aged $>80$ has tripled. The needs of the fastgrowing population of older persons lead to an increasing

Funding: this research was supported by UMCS Institute of Pedagogy Principal Investigator.

Received: April 1, 2020. Accepted: November 2, 2020.

Corresponding author: Anna Kanios, Maria Curie-Skłodowska University, Faculty of Pedagogy and Psychology, Department of Social Pedagogy, Narutowicza 12, 20-031 Lublin, Poland (e-mail: anna.kanios@poczta.umcs.lublin.pl). 
demand for social and medical personnel specializing in this field [3].

The progressing demographic changes also occur in other countries in the EU. In Germany, for example, the demographic burden index was $32.8 \%$ in 2015 and is expected to rise to $46.3 \%$ in 2050 [1]. German experts predict that 300000 additional full-time workers will be needed in the geriatric care sector by 2021. The social policy sector in Germany ensures that older people receive care so as to avoid threats in this respect. It is emphasized that work in the helping professions is physically and intellectually demanding, but it also offers great prospects for the future. An increase in the percentage of dependent older persons results in an increased demand for care. Working as a helping professional can give a lot of satisfaction, but it can also pose a major threat to the personality and interpersonal relations of people whose main responsibility is to provide multi-faceted support to others. Taking care of a senior citizen for several years results in various psychological and physical burdens. Surveys show that about $70 \%$ of carers of older people experience permanent stress, while 50\% suffer from depressive states and depression [4].

In the modern society, an increasing number of people suffer from occupational burnout. While this phenomenon is a major issue today, it is not a new one. Sick leaves resulting from stress and complaints related to burnout constitute one of the biggest threats of the 21st century. Job loss caused by burnout generates high costs for the affected people, businesses and economy. One should not forget about the suffering of individuals affected by burnout and their families, particularly when their relationships disintegrate [5].

According to the latest research on the dynamics of occupational burnout, this phenomenon shows an upward trend. More and more often, human services professionals are affected by this problem. Most researchers agree that a fast growth of this phenomenon poses a particular threat to people in the helping professions who get emotionally involved in their work and are personally confronted with human suffering. These professions include social workers, carers of the elderly as well as healthcare personnel (doctors, nurses), teachers, police officers, psychotherapists and many other professions characterized by direct relations with another human being [6].

Occupational burnout can originate in 3 areas:

- strain caused by clients (clients' characteristics, conflicts of roles, client observations);

- strain in a team of co-workers (too many co-workers in the team, too few co-workers in the team, an unfavorable team composition, a lack of contact and support, the absence of feedback, conceptual incompatibility, rivalry and jealousy, a lack of success, directive management, volunteers);

- strain caused by the institution (staff shortage, a large number of clients, a lack of institutional support for the helpers in their work, ineffectiveness of institutional work, a conflict of roles, a lack of supervision, and the strain felt by the helping professional) [7].

The problem of occupational burnout affects people in the helping professions around the world. Despite the fact that social workers in the USA provide nearly half of mental health services, a low effectiveness of these workers due to burnout risk is also reported [8]. German researchers emphasize, on the other hand, that caregiving staff are under constant stress, which, in the absence of self-reflection (mental hygiene), may lead to serious diseases, mental disorders and, ultimately, occupational burnout $[9,10]$.

In their work, the staff caring for older persons must cope with the deaths of their clients or with difficult patients who do not appreciate the help they receive. Bad atmosphere at work (indifference, disapproval, bullying, rivalry and jealousy) may also have a negative impact on teams and individuals. All these factors increase the risk of occupational stress and, consequently, the sense of occupational burnout. 
In view of the fact that workers in the long-term care sector are exposed to various kinds of occupational strain, it is particularly important to identify such factors and their impact, and to neutralize them through prevention and health promotion [9].

A number of various factors, primarily related to workers' personality, contribute to occupational burnout $[11,12]$.

This paper examines the sense of occupational burnout among workers in the long-term care sector in relation to their personality traits.

According to the World Health Organization, long-term care, in its essence, is the system of activities undertaken by informal caregivers (family, friends, and/or neighbors) and/or professionals (health, social, and others) to ensure that a person who is not fully capable of self-care can maintain the highest possible quality of life, according to his or her individual preferences and requirements, with the greatest possible degree of independence, autonomy, participation, personal fulfillment and human dignity [13].

In accordance with the adopted theoretical and methodological approach, the sense of occupational burnout is construed as the syndrome of emotional exhaustion, depersonalization, and a reduced sense of personal accomplishment [14]. These symptoms most often occur in individuals who work with other people.

The study objective was to examine occupational burnout among workers in the long-term care sector, and to diagnose the differences in the levels of burnout in relation to their personality traits.

The research problem was thus formulated as follows: what is the sense of occupational burnout among workers in the long-term care sector working with older persons, and what are the differences in the sense of burnout among respondents with different personality traits?

It is assumed that there are statistically significant differences among workers in the long-term care sector regarding their sense of occupational burnout (a dependent vari- able) depending on their personality traits (an independent variable). The strength of these differences will vary depending on the value of the variables [7,10,15-19].

The dependent variable in the study is the sense of occupational burnout that can be described by means of the following detailed indices:

- emotional exhaustion,

- depersonalization of the client in professional interactions,

- a reduced sense of personal accomplishment.

Personality traits are the independent variable (neuroticism, extraversion, openness, agreeableness and conscientiousness).

Numerous researchers [20-23] indicate that personality traits are among the sources of occupational burnout. Neuroticism and extraversion are those personality traits that are most frequently correlated with occupational burnout [24]. Studies also show a negative correlation between the emotional exhaustion component of burnout and extraversion [25]. However, of all personality components included in the so-called Big Five, it is neuroticism that shows the strongest connection with occupational burnout. Researchers prove that a high level of neuroticism contributes to the speed of occupational burnout [26,27].

\section{MATERIAL AND METHODS}

In the study, the authors used a diagnostic survey as a method of collecting data of a quantitative character. The following research instruments were used: the $M a$ slach Burnout Inventory (MBI) by C. Maslach (to assess an individual's sense of burnout) and the NEO Five-Factor Inventory (NEO-FFI) by P.T. Costa and R.R. McCrae (to assess personality traits).

In fact, $\mathrm{MBI}$ is the most popular and best standardized instrument. It is a self-description questionnaire containing 22 statements concerning feelings. It assesses 3 dimensions of burnout: emotional exhaustion ( 9 statements), depersonalization ( 5 statements), and the sense of personal 
accomplishment (8 statements). The answers are recorded on a 7-pt scale according to the occurrence frequency of a given feeling: from "never" to "everyday." Cronbach's $\alpha$ was used to determine the internal consistency of the instrument. The value of this coefficient was 0.90 for emotional exhaustion, 0.79 for depersonalization, and 0.71 for the sense of personal accomplishment. In this survey, the following benchmarks (reference levels defined for social services workers) were taken into account:

- emotional exhaustion: low ( $\leq 16 \mathrm{pts})$, medium (17-27 pts), high ( $\geq 28 \mathrm{pts}$ );

- depersonalization: low ( $\leq 5 \mathrm{pts})$, medium (6-10 pts), high ( $\geq 11$ pts);

- the sense of personal accomplishment: low ( $\geq 37 \mathrm{pts})$, medium (36-30 pts), high ( $\leq 29 \mathrm{pts}$ ) [28].

The NEO-FFI instrument is used to diagnose the Big Five personality traits. The inventory encompasses the following 5 scales: neuroticism, extraversion, openness, agreeableness, and conscientiousness. Sten scores were used to distinguish the levels of results, namely a sten score of 1-4 pts was regarded as a low level, 5-6 pts was a medium score, and $7-10$ pts was a high score [19].

The surveys were conducted in Lublin and the Lublin Province where, as statistical data show, the population is ageing.

In 2016, there were 118 assistance centers offering different kinds of support in the Lublin Province, including 25 centers of support for elderly persons (operating in the city of Lublin). Besides, 13 daycare centers and 44 social assistance homes operated in 8 counties of the Lublin Province. There were also 213 social assistance centers in the Province [29]. The survey encompassed all social assistance institutions dedicated to elderly persons and providing long-term care in the city of Lublin and the entire Lublin Province.

A pilot survey was conducted in 2015, while the proper survey was held in 2016. It was carried out in social assistance institutions, social assistance homes (various types), gerontological care centers, and support centers for senior citizens.

The survey procedure began with a request for consent submitted to all the above-mentioned institutions providing assistance to elderly persons. The consent to participate in the survey was obtained only from 50 social assistance centers, 15 social assistance homes, and 7 centers of support for the elderly. The survey respondents were selected using random and non-random sampling. The selection was based on the following criteria: work in the helping profession (such as a social worker, a caregiver in a social assistance home, a community carer, a nurse, and a caregiver for an older person), a varied length of work with elderly persons, belonging to different age groups, employment in an institution providing assistance in different environments in terms of the population size (a village, a town with $\leq 50000$ inhabitants, a town with $50000-100000$ inhabitants, or a town with $>100000$ inhabitants).

The survey encompassed 253 long-term care workers but, ultimately, due to the incompleteness of the data obtained (15 questionnaires were rejected), 238 persons were analyzed. Nonetheless, the sample surveyed is only an approximate reflection of the community at large.

\section{Statistical analyses}

The obtained results were subjected to statistical analysis. The values of the variables analyzed were presented by means of the mean value, the median, and standard deviation, as well as numbers and percentages.

The normality of the distribution of variables in the groups under study was assessed using the Shapiro-Wilk test. The differences between 2 groups were examined using the Mann-Whitney U test. To assess the differences between 3 groups, the analysis of variance (ANOVA) was used along with Tukey's post-hoc test, and, if the conditions for its application were not met, the Kruskal-Wallis non-parametric test was used together with the Bonferroni correction. 
The adopted significance level of $p<0.05$ indicated the existence of statistically significant differences. The database was created and the statistical data analysis was carried out using Statistica 9.1 software (StatSoft, Poland).

\section{RESULTS}

Women were found to constitute a vast majority of staff in the helping professions working with older persons (90.34\%), while men accounted for only $9.66 \%$.

Workers aged 31-35 formed the most numerous age group, representing about one-third $(30.26 \%)$ of the respondents. People aged 36-41 represented about onefourth $(26.89 \%)$ of the surveyed workers in the helping professions. Workers aged 42-50 also represented a considerable proportion of the respondents $(18.07 \%)$, while workers aged $>56$ were the least numerous $(6.30 \%)$.

As the empirical analysis showed, a clear majority of those surveyed $(73.53 \%)$ were married. Every sixth worker $(15.55 \%)$ was single. The smallest proportion of the respondents were divorced $(8.82 \%)$ or widowed persons $(2.1 \%)$.

The survey confirmed a high level of education among workers in the long-term care sector. Most of them (63.87\%) completed a Master's degree program, while $12.18 \%$ completed a Bachelor's degree program. A small proportion of the respondents (12.61\%) had post-secondary $(12.61 \%)$ or secondary education $(11.34 \%)$.

The workers surveyed represented various kinds of helping professions. The biggest proportion of the respondents (70 persons, i.e., 17\%) were social workers who provided care services to older persons. Community carers accounted for $10 \%$, and the same proportion (10.08\%) were carers for older persons. The studied population also comprised carers in a social assistance home $(5.04 \%)$ and persons providing health support to older persons (community nurses and nurses, $4.62 \%$ ).

When analyzing the length of service, such factors as the length of service in general, in the care sector, in the current position of an individual, as well as the length of work with older persons, were taken into account. It turned out that the mean length of service among the workers under study was $>15.86$ years, and the mean length of work with older persons was 11.09 years, similar as in the social assistance sector (12 years).

\section{Sense of occupational burnout among workers in the long-term care sector}

Various survey results show $[8,15,16]$ that the most significant indicators of occupational burnout among workers in the helping professions include stressful working conditions, particularly a lack of rewards, a lack of control, and mental strain caused by the work load.

Emotional exhaustion was the first dimension of occupational burnout that was analyzed. As the data in the table show, a low level of emotional exhaustion occurred in $37.82 \%$ of the respondents. A slightly smaller proportion $(34.03 \%)$ experienced a moderate level of occupational burnout, while a high level of burnout occurred in $28.15 \%$ of the respondents (Table 1).

Depersonalization was the next inventory analyzed. The essence of depersonalization consists of changes in the attitude to other people, manifested in indifferent and dehumanized responses to their problems. People often distance themselves from others, avoid contact and show a cynical attitude to the problems of others. The survey results show that as many as $34.45 \%$ of the workers had a high level of this component of occupational burnout, $30.25 \%$ were coping with stress through a moderate level of depersonalization, and over one-third (35.3\%) showed a low level of depersonalization (Table 1).

A reduced sense of personal accomplishment is linked to the sense of low self-efficacy and helplessness. The quality of the work performed is clearly reduced. Two strategies of behavior can be observed, i.e., extending the duration of working time despite its decreasing efficacy, and a systematic evasion of work duties. At this stage, there 
Table 1. Levels of occupational burnout among workers in the long-term care sector in the survey conducted in Lublin, Poland, in 2016

\begin{tabular}{|c|c|c|}
\hline \multirow{2}{*}{ Occupational burnout levels by inventory } & \multicolumn{2}{|c|}{$\begin{array}{c}\text { Respondents } \\
(\mathrm{N}=238)\end{array}$} \\
\hline & $\mathrm{n}$ & $\%$ \\
\hline \multicolumn{3}{|l|}{ Emotional exhaustion } \\
\hline low level & 90 & 37.82 \\
\hline medium level & 81 & 34.03 \\
\hline high level & 67 & 28.15 \\
\hline \multicolumn{3}{|l|}{ Depersonalization } \\
\hline low level & 84 & 35.30 \\
\hline medium level & 72 & 30.25 \\
\hline high level & 82 & 34.45 \\
\hline \multicolumn{3}{|l|}{ Reduced sense of personal accomplishment } \\
\hline low level & 64 & 26.89 \\
\hline medium level & 57 & 23.95 \\
\hline high level & 117 & 49.16 \\
\hline
\end{tabular}

appears an unwillingness to maintain or establish contacts with clients, a tendency to isolate oneself, escaping work by taking a sick leave, or quitting the job. An increasingly depersonalized attitude to clients results in hostility, uncontrolled emotional outbursts, and a greater number of conflicts with clients and co-workers.

The data in Table 1 show that nearly half of those surveyed (49.16\%) experienced a reduced sense of personal accomplishment at a high level. This component occurred at a medium level in $23.95 \%$, and at a low level in $26.89 \%$, of the respondents (Table 1).

\section{Differences in occupational burnout}

\section{among respondents with different personality traits}

A statistically significant difference in terms of emotional exhaustion was observed between the respondents with different levels of neuroticism $(p<0.001)$. The respondents with a low level of neuroticism had a significantly lower result in the emotional exhaustion inventory
$(\mathrm{M}=1.91)$ (indicating a lower degree of burnout) than those with a medium $(\mathrm{M}=2.41)$ and high $(\mathrm{M}=3.09)$ level of neuroticism. At the same time, the respondents with a high level of neuroticism had the highest result in the emotional exhaustion inventory $(\mathrm{M}=3.09)$ - also significantly higher than the respondents with a medium level of neuroticism $(\mathrm{M}=2.41)$.

Statistically significant differences depending on the level of neuroticism were also observed in terms of depersonalization $(\mathrm{p}<0.001)$. Also in this case, the lowest result in the depersonalization inventory (indicating a lower degree of burnout, a result significantly lower than the one achieved by the group with a medium and high level of neuroticism) was obtained by the workers with a low level of neuroticism $(\mathrm{M}=1.29)$; the highest result occurred in the group with the highest level of neuroticism $(\mathrm{M}=2.33)$. The respondents with a medium level of neuroticism had a significantly higher result for depersonalization $(\mathrm{M}=1.80)$ than those with a low level of neuroticism $(M=1.29)$, and significantly lower than those with a high level of neuroticism $(\mathrm{M}=2.33)$.

In the case of the personal accomplishment inventory, the respondents with a low level of neuroticism had a significantly higher result $(\mathrm{M}=4.19$, indicating a lower degree of burnout) than the persons with a medium $(\mathrm{M}=3.59)$ and high $(\mathrm{M}=3.7)$ level of neuroticism. No statistically significant differences were found between the group with a medium and high level of neuroticism as regards personal accomplishment (Table 2).

A statistically significant difference in terms of emotional exhaustion was observed between the respondents with different levels of extraversion $(p<0.001)$. The respondents with a low level of extraversion had the highest result in the emotional exhaustion inventory $(\mathrm{M}=2.87$, indicating a high degree of occupational burnout). The respondents with a medium level of extraversion $(\mathrm{M}=2.61)$ also had a relatively high result in this inventory. At the same time, the respondents with a high level of extraversion had 
Table 2. Differences in occupational burnout among the respondents with different levels of neuroticism in the survey conducted in Lublin, Poland, in 2016

\begin{tabular}{|c|c|c|c|c|c|c|c|c|c|c|c|c|}
\hline \multirow{3}{*}{ Occupational burnout } & \multicolumn{9}{|c|}{ Neuroticism inventory results } & \multirow{3}{*}{$F(2,235)$} & \multirow{3}{*}{$\mathrm{p}$} & \multirow{3}{*}{$\begin{array}{c}\text { Differences } \\
\text { between groups }\end{array}$} \\
\hline & \multicolumn{3}{|c|}{ low } & \multicolumn{3}{|c|}{ medium } & \multicolumn{3}{|c|}{ high } & & & \\
\hline & $\mathrm{M}$ & $\mathrm{Me}$ & SD & $\mathrm{M}$ & $\mathrm{Me}$ & $\mathrm{SD}$ & $\mathrm{M}$ & $\mathrm{Me}$ & SD & & & \\
\hline Emotional exhaustion & 1.91 & 1.63 & 1.14 & 2.41 & 2.38 & 1.09 & 3.09 & 3 & 1.29 & 19.374 & $<0.001$ & L-M, L-H, M-H \\
\hline Depersonalization & 1.29 & 1.2 & 0.85 & 1.8 & 1.6 & 1.13 & 2.33 & 2.3 & 1.4 & 15.753 & $<0.001$ & L-M, L-H, M-H \\
\hline Personal accomplishment & 4.19 & 4.25 & 1.1 & 3.59 & 3.44 & 1.25 & 3.37 & 3.44 & 1.05 & 10.543 & $<0.001$ & L-M, L-H \\
\hline
\end{tabular}

L - low level; $\mathrm{M}$ - medium level; $\mathrm{H}$ - high level.

$\mathrm{F}$ - analysis of variance (ANOVA).

Table 3. Differences in occupational burnout among the respondents with different levels of extraversion in the survey conducted in Lublin, Poland, in 2016

\begin{tabular}{|c|c|c|c|c|c|c|c|c|c|c|c|c|}
\hline \multirow{3}{*}{ Occupational burnout } & \multicolumn{9}{|c|}{ Extraversion inventory results } & \multirow{3}{*}{$F(2,235)$} & \multirow{3}{*}{$\mathrm{p}$} & \multirow{3}{*}{$\begin{array}{c}\text { Differences } \\
\text { between groups }\end{array}$} \\
\hline & \multicolumn{3}{|c|}{ low } & \multicolumn{3}{|c|}{ medium } & \multicolumn{3}{|c|}{ high } & & & \\
\hline & $\mathrm{M}$ & $\mathrm{Me}$ & SD & M & $\mathrm{Me}$ & $\mathrm{SD}$ & $\mathrm{M}$ & $\mathrm{Me}$ & SD & & & \\
\hline Emotional exhaustion & 2.87 & 2.75 & 1.16 & 2.61 & 2.63 & 1.26 & 1.9 & 1.75 & 1.13 & 13.016 & $<0.001$ & L-H, M-H \\
\hline Depersonalization & 2.07 & 2 & 1.12 & 1.96 & 1.6 & 1.27 & 1.34 & 1.2 & 1.05 & 8.688 & $<0.001$ & L-H, M-H \\
\hline Personal accomplishment & 3.17 & 3 & 0.94 & 3.63 & 3.63 & 1.1 & 4.27 & 4.5 & 1.25 & 17.202 & $<0.001$ & L-M, L-H, M-H \\
\hline
\end{tabular}

Abbreviations as in Table 2.

the lowest result in the emotional exhaustion inventory $(\mathrm{M}=1.9)$.

Similar differences were observed in the case of depersonalization. Statistically significant differences depending on the level of extraversion were also observed in the depersonalization inventory $(\mathrm{p}<0.001)$. The lowest result in the depersonalization inventory (indicating a lower degree of burnout) was obtained by the workers with a high level of extraversion $(\mathrm{M}=1.34)$, while the highest result occurred in the group with a low level of extraversion $(\mathrm{M}=2.07)$. The respondents with a medium level of extraversion had a significantly higher result for depersonalization $(\mathrm{M}=1.96)$ than those with a high level of extraversion.

As regards personal accomplishment, statistically significant differences occurred between the groups of persons with different levels of extraversion. The respondents with a high level of extraversion had a higher result
$(\mathrm{M}=4.27$, indicating a lower degree of burnout $)$ than those with a medium $(\mathrm{M}=3.63)$ and low $(\mathrm{M}=3.17)$ level of extraversion. No statistically significant differences were found between the group with a medium and high level of neuroticism in the case of personal accomplishment (Table 3).

When it comes to the differences between occupational burnout and openness to experience, significant differences occurred only in terms of personal accomplishment. The workers with a high level of openness to experience achieved the highest result with regard to personal accomplishment $(\mathrm{M}=4.21)$. The respondents with a medium $(\mathrm{M}=3.63)$ and low level of openness to experience $(\mathrm{M}=3.64)$ achieved comparable results for personal accomplishment although they were lower than among the respondents with a high level of openness (Table 4). 
Table 4. Differences in occupational burnout among the respondents with different levels of openness in the survey conducted in Lublin, Poland, in 2016

\begin{tabular}{|c|c|c|c|c|c|c|c|c|c|c|c|c|}
\hline \multirow{3}{*}{ Occupational burnout } & \multicolumn{9}{|c|}{ Openness inventory results } & \multirow{3}{*}{$\mathrm{H}(2,238)$} & \multirow{3}{*}{$\mathrm{p}$} & \multirow{3}{*}{$\begin{array}{l}\text { Differences } \\
\text { between groups }\end{array}$} \\
\hline & \multicolumn{3}{|c|}{ low } & \multicolumn{3}{|c|}{ medium } & \multicolumn{3}{|c|}{ high } & & & \\
\hline & $\mathrm{M}$ & $\mathrm{Me}$ & SD & $\mathrm{M}$ & $\mathrm{Me}$ & SD & $\mathrm{M}$ & $\mathrm{Me}$ & SD & & & \\
\hline Emotional exhaustion & 2.28 & 2.13 & 1.13 & 2.53 & 2.5 & 1.39 & 2.46 & 2.5 & 1.06 & 1.359 & 0.507 & - \\
\hline Depersonalization & 1.83 & 1.6 & 1.19 & 1.77 & 1.4 & 1.25 & 1.69 & 1.4 & 1.11 & 0.43 & 0.806 & - \\
\hline Personal accomplishment & 3.64 & 3.5 & 1.08 & 3.63 & 3.63 & 1.19 & 4.21 & 4.38 & 1.28 & 8.617 & 0.135 & L-H, M-H \\
\hline
\end{tabular}

$\mathrm{H}$ - Kruskal-Wallis test.

Other abbreviations as in Table 2.

Table 5. Differences in occupational burnout among the respondents with different levels of agreeableness in the survey conducted in Lublin, Poland, in 2016

\begin{tabular}{|c|c|c|c|c|c|c|c|c|c|c|c|c|}
\hline \multirow{3}{*}{ Occupational burnout } & \multicolumn{9}{|c|}{ Agreeableness inventory results } & \multirow{3}{*}{$\mathrm{F}(2,235)$} & \multirow{3}{*}{$\mathrm{p}$} & \multirow{3}{*}{$\begin{array}{c}\text { Differences } \\
\text { between groups }\end{array}$} \\
\hline & \multicolumn{3}{|c|}{ low } & \multicolumn{3}{|c|}{ medium } & \multicolumn{3}{|c|}{ high } & & & \\
\hline & $\mathrm{M}$ & $\mathrm{Me}$ & $\mathrm{SD}$ & $\mathrm{M}$ & $\mathrm{Me}$ & SD & $\mathrm{M}$ & $\mathrm{Me}$ & SD & & & \\
\hline Emotional exhaustion & 2.93 & 3 & 1.31 & 2.38 & 2.25 & 1.2 & 1.95 & 1.75 & 1.06 & 12.263 & $<0.001$ & L-H, L-M \\
\hline Depersonalization & 2.58 & 2.7 & 1.32 & 1.57 & 1.3 & 0.9 & 1.17 & 0.8 & 0.94 & 34.68 & $<0.001$ & L-H, L-M \\
\hline Personal accomplishment & 3.42 & 3.38 & 1.14 & 3.65 & 3.69 & 1.16 & 4.19 & 4.38 & 1.16 & 8.407 & $<0.001$ & L-H, M-H \\
\hline
\end{tabular}

Abbreviations as in Table 2.

Significant differences were also observed between the agreeableness of workers in the helping professions and the specific components of occupational burnout. The workers with a high level of agreeableness achieved the highest results with regard to personal accomplishment and the lowest results with regard to depersonalization. On the other hand, the workers with a low level of this personality trait demonstrated the highest results with regard to emotional exhaustion (Table 5).

These analyses show that the long-term care workers with a low level of conscientiousness achieved that highest results $(\mathrm{M}=2.74)$, while the respondents with a high level of this personality trait had lower results $(M=1.99)$ with regard to emotional exhaustion. The respondents with a medium level of conscientiousness also achieved medium results with regard to emotional exhaustion $(\mathrm{M}=2.58)$.
The respondents with a low level of conscientiousness achieved a high result with regard to depersonalization $(\mathrm{M}=2.18)$, while those with a high level of conscientiousness achieved low results in this regard $(\mathrm{M}=1.27)$. The respondents with a medium level of conscientiousness also achieved medium results with regard to depersonalization $(\mathrm{M}=1.9)$.

Personal accomplishment was the last component of occupational burnout to be analyzed. The following trend was observed: the higher the level of conscientiousness, the higher the results with regard to personal accomplishment $(\mathrm{M}=4.63)$. On the other hand, a low level of this personality trait was correlated with low results $(\mathrm{M}=3.04)$. The respondents with a medium level of conscientiousness achieved medium results with regard to personal accomplishment $(\mathrm{M}=3.73)$ (Table 6). 
Table 6. Differences in occupational burnout among the respondents with different levels of conscientiousness in the survey conducted in Lublin, Poland, in 2016

\begin{tabular}{|c|c|c|c|c|c|c|c|c|c|c|c|c|}
\hline \multirow{3}{*}{ Occupational burnout } & \multicolumn{9}{|c|}{ Conscientiousness inventory results } & \multirow{3}{*}{$\mathrm{F}(2,235)$} & \multirow{3}{*}{$\mathrm{p}$} & \multirow{3}{*}{$\begin{array}{c}\text { Differences } \\
\text { between groups }\end{array}$} \\
\hline & \multicolumn{3}{|c|}{ low } & \multicolumn{3}{|c|}{ medium } & \multicolumn{3}{|c|}{ high } & & & \\
\hline & $\mathrm{M}$ & $\mathrm{Me}$ & SD & $\mathrm{M}$ & $\mathrm{Me}$ & SD & $\mathrm{M}$ & $\mathrm{Me}$ & SD & & & \\
\hline Emotional exhaustion & 2.74 & 2.63 & 1.25 & 2.58 & 2.63 & 1.2 & 1.99 & 1.75 & 1.2 & 8.524 & $<0.001$ & $\mathrm{~L}-\mathrm{H}, \mathrm{M}-\mathrm{H}$ \\
\hline Depersonalization & 2.18 & 2. & 1.21 & 1.9 & 1.6 & 1.19 & 1.27 & 1. & 1.02 & 13.415 & $<0.001$ & L-H, M-H \\
\hline Personal accomplishment & 3.04 & 3 & 0.95 & 3.73 & 3.81 & 1.06 & 4.41 & 4.63 & 1.13 & 33.768 & $<0.001$ & L-M, L-H, M-H \\
\hline
\end{tabular}

Abbreviations as in Table 2.

\section{DISCUSSION}

The phenomenon of occupational burnout can be observed particularly among persons in the helping professions whose work is based on helping and having close contacts with other people. These are, among others, healthcare employees, i.e., doctors, nurses, psychologists, as well as social workers and caregivers to elderly persons. Workers in the long-term care sector probably fit the above description.

The survey results indicate that there are significant differences among the workers surveyed with regard to 2 occupational burnout inventories, i.e., emotional exhaustion and depersonalization. Basically, they can be divided into 3 groups, i.e., those at a high, medium and low risk of occupational burnout. It is worth noting that nearly half of the workers experienced a highly reduced sense of personal accomplishment. Furthermore, statistically significant differences were observed between the sense of occupational burnout and personality traits of the workers surveyed in all the inventories analyzed. Thus, the working hypothesis has been confirmed. It was observed that the persons with a lower level of neuroticism had a lower level of emotional exhaustion and depersonalization, as well as a higher result with regard to personal accomplishment. A relationship between the level of neuroticism and the specific components of occupational burnout has already been observed in earlier research [30,31].
The correlation of personality traits with neuroticism and extraversion has been described quite well in the literature $[32,33]$. The present study is consistent with previous research where it was observed that neuroticism triggers a sense of exhaustion and exasperation, as well as a loss of interest in one's work. Extraversion, on the contrary, reduces the levels of emotional exhaustion and depersonalization [34].

The persons with a high level of extraversion obtained a low result with regard to depersonalization and a high result with regard to emotional exhaustion.

These correlations are consistent with the results of other surveys conducted in groups of teachers, paramedics, or nurses, i.e., members of the helping professions [24,35].

The higher the results with regard to openness to experience, the better the outcomes with regard to personal accomplishment and, consequently, the lower the risk of occupational burnout.

The higher the level of agreeableness of the respondents, the higher their results with regard to personal accomplishment, and the lower the results concerning depersonalization. Agreeableness is a personality factor that indicates someone's attitude to other people, and the willingness to cooperate, provide help, and display trust and selflessness in relations with others. It is from this perspective that the correlation between agreeableness and depersonalization can be understood. 
Table 7. Differences in occupational burnout by sex of the respondents in the survey conducted in Lublin, Poland, in 2016

\begin{tabular}{|c|c|c|c|c|c|c|c|c|}
\hline \multirow{3}{*}{ Occupational burnout } & \multicolumn{6}{|c|}{$\begin{array}{c}\text { Respondents } \\
(\mathrm{N}=238)\end{array}$} & \multirow{3}{*}{$\mathrm{Z}$} & \multirow{3}{*}{$\mathrm{p}$} \\
\hline & \multicolumn{3}{|c|}{$\begin{array}{c}\text { women } \\
(\mathrm{N}=215)\end{array}$} & \multicolumn{3}{|c|}{$\begin{array}{c}\text { men } \\
(\mathrm{N}=23)\end{array}$} & & \\
\hline & M & $\mathrm{Me}$ & SD & M & $\mathrm{Me}$ & SD & & \\
\hline Emotional exhaustion & 2.44 & 2.38 & 1.23 & 2.39 & 2.13 & 1.45 & 0.351 & 0.726 \\
\hline Depersonalization & 1.71 & 1.40 & 1.17 & 2.38 & 2.40 & 1.38 & -2.231 & 0.026 \\
\hline Personal accomplishment & 3.75 & 3.75 & 1.18 & 3.61 & 3.38 & 1.31 & 0.585 & 0.559 \\
\hline
\end{tabular}

Z - Mann-Whitney U test.

Conscientiousness indicates persistence, accuracy, good organization, self-discipline, and reliability, which all translate to efficacy at work. This, in turn, can be a factor protecting against stressors and strains at work.

It was found that the persons with a low level of conscientiousness were more susceptible to emotional exhaustion and depersonalization, while those with a high level of this personality trait achieved high results with regard to personal accomplishment.

These results are consistent with the results obtained in other studies [36].

With the knowledge about the relationships between personality traits and the components of occupational burnout, it is possible to conduct screening tests aimed at determining the group that is potentially the most vulnerable to occupational burnout.

The respondents experiencing occupational burnout were also analyzed according to their socio-demographic characteristics such as sex, age, the level of education and the length of service.

The survey results showed that women were more susceptible to emotional exhaustion $(\mathrm{M}=2.44)$ than men $(\mathrm{M}=2.39)$. On the other hand, men were more susceptible to depersonalization $(\mathrm{M}=2.38)$ than women $(\mathrm{M}=1.71)$. In the case of personal accomplishment, it turns out that women achieved higher results $(\mathrm{M}=3.75)$ than men $(\mathrm{M}=3.61)$, which indicates a lower level of burnout among women. The obtained results are consistent with the findings made by other researchers [37,38] (Table 7). The analyses revealed that the differences in the sense of burnout were not statistically significant among the respondents in different age groups. However, a trend could be observed that the risk of occupational burnout increased with the age of the workers surveyed. The highest mean results $(\mathrm{M}=2.38)$ were observed in the age group of $\leq 35$ years, i.e., in relatively young persons, while the highest results in the age group of $>45$ years $(\mathrm{M}=2.58)$ (Table 8$)$.

Statistically significant differences in occupational burnout occurred in terms of the respondents' level of education. It was observed that the higher the level of education of the respondents, the lower the risk of experiencing occupational burnout. As regards emotional exhaustion, the people with higher education received lower mean results $(M=2.34)$ than those with secondary education $(\mathrm{M}=2.72)$. A similar trend could be observed for depersonalization. On the other hand, the risk of a reduced sense of personal accomplishment was lower among the respondents with higher education (Table 9).

The survey also showed that the risk of emotional exhaustion increased with the length of service. The lowest result $(\mathrm{M}=2.13)$ in this inventory was obtained in the group with a short length of service ( $\leq 5$ years), while the highest result $(\mathrm{M}=2.51)$ in the group of people who had worked for $>15$ years (Table 10$)$. 
Table 8. Differences in occupational burnout by age of the respondents in the survey conducted in Lublin, Poland, in 2016

\begin{tabular}{|c|c|c|c|c|c|c|c|c|c|c|c|}
\hline \multirow{3}{*}{ Occupational burnout } & \multicolumn{9}{|c|}{$\begin{array}{l}\text { Respondents } \\
(\mathrm{N}=238)\end{array}$} & \multirow{3}{*}{$\begin{array}{l}F(2,235) \\
H(2,238)\end{array}$} & \multirow{3}{*}{$\mathrm{p}$} \\
\hline & \multicolumn{3}{|c|}{$\begin{array}{l}\leq 35 \text { years } \\
(\mathrm{N}=94)\end{array}$} & \multicolumn{3}{|c|}{$\begin{array}{c}36-45 \text { years } \\
(\mathrm{N}=64)\end{array}$} & \multicolumn{3}{|c|}{$\begin{array}{l}>45 \text { years } \\
(\mathrm{N}=80)\end{array}$} & & \\
\hline & M & $\mathrm{Me}$ & $\mathrm{SD}$ & M & $\mathrm{Me}$ & SD & M & $\mathrm{Me}$ & SD & & \\
\hline Emotional exhaustion & 2.38 & 2.25 & 1.25 & 2.33 & 2.44 & 1.19 & 2.58 & 2.50 & 1.30 & $1.166^{\mathrm{b}}$ & 0.558 \\
\hline Depersonalization & 1.74 & 1.40 & 1.21 & 1.78 & 1.50 & 1.16 & 1.82 & 1.60 & 1.24 & $0.169^{\mathrm{b}}$ & 0.919 \\
\hline Personal accomplishment & 3.60 & 3.56 & 1.12 & 3.80 & 3.81 & 1.07 & 3.83 & 3.88 & 1.35 & $0.993^{\mathrm{a}}$ & 0.372 \\
\hline
\end{tabular}

Abbreviations as in Table 2.

Table 9. Differences in occupational burnout by level of education of the respondents in the survey conducted in Lublin, Poland, in 2016

\begin{tabular}{|c|c|c|c|c|c|c|c|c|}
\hline \multirow{3}{*}{ Occupational burnout } & \multicolumn{6}{|c|}{$\begin{array}{l}\text { Respondents } \\
(\mathrm{N}=238)\end{array}$} & \multirow{3}{*}{$\mathrm{Z}$} & \multirow{3}{*}{$\mathrm{p}$} \\
\hline & \multicolumn{3}{|c|}{$\begin{array}{l}\text { higher education } \\
\qquad(\mathrm{N}=152)\end{array}$} & \multicolumn{3}{|c|}{$\begin{array}{l}\text { secondary education } \\
\qquad(\mathrm{N}=86)\end{array}$} & & \\
\hline & M & $\mathrm{Me}$ & SD & M & $\mathrm{Me}$ & SD & & \\
\hline Emotional exhaustion & 2.34 & 2.13 & 1.24 & 2.72 & 2.63 & 1.25 & -1.952 & 0.051 \\
\hline Depersonalization & 1.77 & 1.40 & 1.21 & 1.80 & 1.60 & 1.20 & -0.301 & 0.764 \\
\hline Personal accomplishment & 3.79 & 3.75 & 1.13 & 3.56 & 3.50 & 1.34 & 1.045 & 0.296 \\
\hline
\end{tabular}

Z - Mann-Whitney U test.

Table 10. Differences in occupational burnout by length of service of the respondents in the survey conducted in Lublin, Poland, in 2016

\begin{tabular}{|c|c|c|c|c|c|c|c|c|c|c|c|}
\hline \multirow{3}{*}{ Occupational burnout } & \multicolumn{9}{|c|}{$\begin{array}{l}\text { Respondents } \\
(\mathrm{N}=238)\end{array}$} & \multirow{3}{*}{$\mathrm{H}(2,238)$} & \multirow{3}{*}{$\mathrm{p}$} \\
\hline & \multicolumn{3}{|c|}{$\begin{array}{l}\leq 5 \text { years } \\
(\mathrm{N}=33)\end{array}$} & \multicolumn{3}{|c|}{$\begin{array}{l}\text { 6-15 years } \\
(\mathrm{N}=163)\end{array}$} & \multicolumn{3}{|c|}{$\begin{array}{l}>15 \text { years } \\
(\mathrm{N}=42)\end{array}$} & & \\
\hline & $\mathrm{M}$ & $\mathrm{Me}$ & SD & $\mathrm{M}$ & $\mathrm{Me}$ & SD & $\mathrm{M}$ & $\mathrm{Me}$ & SD & & \\
\hline Emotional exhaustion & 2.13 & 1.88 & 1.25 & 2.47 & 2.50 & 1.23 & 2.51 & 2.50 & 1.35 & 1.927 & 0.382 \\
\hline Depersonalization & 1.59 & 1.40 & 1.12 & 1.66 & 1.70 & 1.29 & 1.93 & 1.40 & 1.20 & 2.649 & 0.266 \\
\hline Personal accomplishment & 3.55 & 3.50 & 1.25 & 3.75 & 3.75 & 1.03 & 3.91 & 4.00 & 1.31 & 2.794 & 0.247 \\
\hline
\end{tabular}

\section{Limitations of the survey}

The survey was conducted on a relatively small sample and in the territory of only 1 province in Poland, which may have impacted on the results obtained. In the future, a greater number of persons should be surveyed, and the survey should encompass the entire country. The occupational burnout survey was based on Maslach's model. Other models can be used in the future, e.g. the Link 
Burnout Questionnaire - a model that enables the assessment of 4 aspects of occupational burnout: psychophysical exhaustion, deterioration of relations with clients, the sense of inefficacy, and disappointment [39].

\section{CONCLUSIONS}

The survey results confirm the existence of the risk of occupational burnout. These results should inspire the development of strategies aimed at preventing occupational burnout in long-term care workers at the level of individuals and institutions, as well as with respect to systemic solutions within the national social policy, for ensuring the mental health of workers and maintaining a high quality of social services.

It is very important to take timely preventive measures, particularly at the institutional level, in order to promote and preserve the health of workers in the long-term care sector. Supervision, coaching, conflict management and the prevention of intimidation can help workers in coping with conflicts and stressful situations so that they do not lead to their occupational burnout. The personality traits of workers should certainly be taken into consideration when designing preventive measures. A good way of coping with burnout syndrome is mental training that can help people rally their inner strength, increase their energy and enhance the joy of life. However, taking care of oneself during work is what many workers neglect to do. Therefore, measures aimed at preventing burnout should be suited to the personality of individual workers. Therefore, personality assessment instruments are particularly important to diagnose workers susceptible to emotional exhaustion so that they can be encompassed by dedicated prevention programs and personalized interventions both at the individual and organization level [40].

At present, burnout prevention is a priority in many European countries, e.g., in Germany. Targeted prevention and early detection of this threat is of key importance [41,42]. Targeted interventions should be undertaken to reduce the likelihood of diseases and undesirable physical or mental states, and to prevent or at least delay their occurrence [43]. Supervision is one of such intervention methods; it is aimed at strengthening one's personality and fostering self-reflection in relation to individual will. Supervision is also a method of improving the communication between various professional groups [44].

Persons affected by occupational burnout have a negative impact on the quality of care. Other ways of counteracting burnout include coaching and feedback. Coaching is a form of counseling aimed at improving the professional potential and enhancing satisfaction with work. It promotes selfawareness and self-observation, as well as reflects perspectives supporting and developing the possible actions and preventive measures [45]. Regular feedback should also be provided in order to solve various conflicts that may accumulate and may be impossible to solve by an individual on their own. It also guarantees an improvement in cooperation. Team members must demonstrate mutual openness for the feedback method to yield positive results.

\section{REFERENCES}

1. Tracz-Dral J. [Population ageing in the European Union: current state and forecast] [Internet]. Warszawa: Chancellery of the Senate; 2018 [cited 2020 Jan 11]. Available from: https:// www.senat.gov.pl/gfx/senat/pl/senatopracowania/160/plik/ot662.pdf. Polish.

2. Błędowski P. [Ageing as a social problem. Prospects of demographic ageing in Poland until 2035]. In: Mossakowska M, Więcek A, Błędowski P, editors. [Medical, psychological, sociological and economic aspects of aging in Poland]. Poznań: Termedia; 2012. p. 12-23. Polish.

3. Grodzicki T. [Staff and system of medical care for the elderly. Cooperation between various sectors - necessary changes]. In: [Report of the Supreme Audit Office. Medical care of the elderly at the threshold of a demographic revolution] [Internet]. Warszawa; 2016 [cited 2020 Feb 10]. Available from: www.nik.gov.pl/plik/id,10370.pdf. Polish. 
4. Gauthier S. Clinical Diagnosis and Management of Alzheimer's Disease. London: Martin Dunitz Publishers; 1996.

5. Demerouti E, Nachreiner F, Bakker AB. Schaufeli WB. The job demands-resources model of burnout. J Appl Psychol. 2001;86(3):119-30, https://doi.org/10.1037/0021-9010. 86.3.499.

6. Zbyrad T. [Occupational burnout risk in social service workers]. Ann Univ Mariae Curie-Skłodowska J Paedagog Psychol. 2017;30(4), https://doi.org/10.17951/j.2017.30.4.87. Polish.

7. Fengler J. [Helping is tiring. Occupational burnout]. Gdańsk: Gdańskie Wydawnictwo Psychologiczne; 2000. Polish.

8. Rubin A, Parrish DE. Comparing Social Worker and NonSocial Worker Outcomes: A Research Review. Soc Work. 2012;57(4), https://doi.org/10.1093/sw/sws015.

9. Schewior-Popp S, Sitzmann F, Ullrich L. [Thiemes Care: Textbook for caregivers in training, 12. ed.]. Stuttgart: Georg Thieme Verlag KG; 2012. German.

10. Terelak JF. [Organisational stress]. Warszawa: Oficyna Wydawnicza; 2005. Polish.

11. Mojsa-Kaja J, Golonka K, Marek T. Job burnout and engagement among teachers - Worklife areas and personality traits as predictors of relationships with work. Int J Occup Med Environ Health. 2015;28(1):102-19, https://doi. org/10.13075/ijomeh.1896.00238.

12. Waldmann C, Wolfrad U, Klement A, Fuchs S, Riemenschneider H, Heise M. [About the relationship between personality traits and burnout risks]. Prävention und Gesundheitsförderung. 2017;12(1):60-72. German.

13. World Health Organization. Towards an international consensus on policy for long-term care of the ageing [Internet]. Geneva: The Organization; 2000 [cited 2020 Feb 20]. Available from: https://www.who.int/ageing/publications/long_term_ care/en/. Polish.

14. Maslach Ch. [Burnout from a multidimensional perspective]. In: Sęk $\mathrm{H}$, editor. [Occupational burnout, causes, mechanisms, prevention]. Warszawa: PWN; 2000. p. 13-31. Polish.

15. Maslach C, Jackson SE, Leiter MP. Maslach Burnout Inventory Manual. California: Consulting Psychologists Press; 1996.
16. Bańka A. [Labour psychology]. In: Strelau J, editor. [Psychology. Academic Textbook]. Gdańsk: Gdańskie Wydawnictwo Psychologiczne; 2000. p. 306-34. Polish.

17. Ogińska-Bulik N. [Occupational stress in the social services professions]. Warszawa: Difin; 2006. Polish.

18. Sęk H. [Occupational burnout in teachers. Determinants and possibilities of prevention]. In: Sęk H, editor. [Occupational burnout. Causes and prevention]. Warszawa: PWN; 2007. p. 149-69. Polish.

19. Zawadzki B, Strelau J, Szczepaniak P, Śliwińska M. [The NEO FFI Personality Inventory by Costa and McCrae]. Warszawa: Pracownia Testów Psychologicznych Polskiego Towarzystwa Psychologicznych; 1998. Polish.

20. Costa PT, McCrae RR. Normal personality assessment in clinical practice: The NEO Personality Inventory. Psychol Assess. 1992;4(1):5-13, https://doi.org/10.1037/1040-3590.4.1.5.

21. Grunt-Mejer K. [Occupational burnout as a factor reducing the level of safety at work]. Bezpiecz Pr. 2012;4(487):12-4. Polish.

22. Sygit-Kowalkowska E, Weber-Rajek M, Herkt M, Ossowski R. [Burnout in officers of the prison service units. The role of personality and selected professional characteristics]. Med Pr. 2017;68(1):85-94, https://doi.org/10.13075/mp.5893. 00499. Polish.

23. Homayooni A, Homayooni F. Homayooni S. The relationship between personality traits, basic psychological needs satisfaction, work-related psychological flexibility and job burnout. Iran Occup Health. 2020;16(6):27-39.

24. Manlove EE. Multiple correlates of burnout in child care workers: Early Child Res Q. 1993;8(4):499-518, https://doi. org/10.1016/S0885-2006(05)80082-1.

25. Becker G. NEO-FFI scores in college men and women: A view from McDonald's unified treatment of test theory. J Res Pers. 2006;40(6):911-41, https://doi.org/10.1016/j.jrp. 2005.09.009.

26. Ghorpade J, Lackritz J, Singh G. Burnout and personality: Evidence from academia. J Career Assess. 2007;15(2):24056, https://doi.org/10.1177/1069072706298156. 
27. Zeng C, Shi K. Relationship of big five personality with employees' job burnout. Chin J Clin Psychol. 2007;15(6): 614-16.

28. Anczewska M. [Stress and occupational burnout in psychiatric healthcare staff]. Warszawa: Instytut Psychiatrii i Neurologii; 2006. Polish.

29. [Assessment of social assistance resources in 2016] [Internet]. Lublin: 2017 [cited 2020 Jul 19]. Available from: http:// rops.lubelskie.pl/wp-content/uploads/2017/08/OZPS-za2016-po-Sejmiku.pdf. Polish.

30. Bakker AB, Van Der Zee KI, Lewig KA, Dollard MF. The relationship between the Big Five personality factors and burnout: A study among volunteer counselors. J Soc Psychol. 2006;146(1):31-50, https://doi.org/10.3200/SOCP.146. 1.31-50.

31. Kim HJ, Shin KH, Swanger N. Burnout and engagement: A comparative analysis using the Big Five personality dimensions. Int J Hosp Manag. 2009;28(1):96-104, https://doi. org/10.1016/j.ijhm.2008.06.001.

32. Schaufeli WB, Enzman D. The burnout companion to study and practice: A critical analysis. London: Taylor and Francis; 1998.

33. Fontana D, Abouserie R. Stress levels, gender and personality factors in teachers. Br J Educ Psychol. 1993;63(2):261-70, https://doi.org/10.1111/j.2044-8279.1993.tb01056.x.

34. Cano-Garcia EJ, Padilla-Munoz EM, Carrasco-Ortiz M.A. Personality and contextual variables in teacher burnout. Pers Individ Differences. 2005;38:929-40, https://doi. org/10.1016/j.paid.2004.06.018.

35. Mojsa-Kaja J, Golonka K, Marek T. Job burnout and engagement among teachers - Worklife Areas and personality traits as predictors of relationships with work. Int J Occup Med Environ Health. 2018;(1):102-19, https://doi.org/10.13075/ ijomeh.1896.00238.
36. Ghorpade J, Lackritz J, Singh G. Burnout and personality: Evidence from academia. J Career Assess. 2007;15(2): 240-56, https://doi.org/10.1177/1069072706298156.

37. Adam S, Mohos M, Kalabay L, Torza P. Potential correlates of burnout among general practitioners and residents in Hungary: the significant role of gender, age, dependant care and experience. BMC Fam Pract. 2018;19(193), https://doi. org/10.1186/s12875-018-0886-3.

38. Eden AR, Jabbarpour Y, Morgan ZJ, Wilkinson E, Peterson LE. Burnout among family physicians by gender and age. J Am Board Fam Med. 2020;33(3):355-6, https://doi. org/10.3122/jabfm.2020.03.190319.

39. Jaworowska A. [Massimo Santinello's Occupational Burnout Inventory]. Warszawa: Pracownia Testów Psychologicznych PTP; 2014. Polish.

40. Grigorescu S, Cazan AM, Grigorescu OD, Rogozea LM. The role of the personality traits and work characteristics in the prediction of the burnout syndrome among nurses - a new approach within predictive, preventive, and personalized medicine concept, EPMA J. 2018:355-65, https://doi.org/10. 1007/s13167-018-0151-9.

41. Schmidt S, Meißner T. [Organisation and liability in outpatient care]. Heidelberg: Springer Medizin Verlag; 2009. German.

42. Günüssen NP, Ustün B. An RCT of coping and support groups to reduce burnout among nurses. Int Nurs Rev. 2010;57:48592, https://doi.org/10.1111/j.1466-7657.2010.00808.x.

43. Hurrelmann K, Klotz T, Haisch J. [Textbook on prevention and health promotion, 2nd ed.]. Bern: Huber; 2007. German.

44. Domnovsky M. [Burnout and stress in the helping professions: Mental training to successfully overcome crisis, 2nd ed.]. Hannover: Brigitte Kunz Verlag; 2005. German.

45. Kowalzik U. [Successful staff development: What care facilities and services can do in this respect]. Hannover: Schlütersche Verlagsgesellschaft; 2007. German.

This work is available in Open Access model and licensed under a Creative Commons Attribution-NonCommercial 3.0 Poland License - http://creativecommons.org/ licenses/by-nc/3.0/pl/deed.en. 